\title{
How can surgeonfish help pediatric surgeons? A pilot study investigating the antinociceptive effect of fish aquariums in adult volunteers
}

\author{
Matthieu Sanchez MD ${ }^{1}$, Marion Delpont MD ${ }^{1}$, Manon Bachy MD ${ }^{1}$, Reda Kabbaj MD ${ }^{1}$, \\ Daniel Annequin MD², Raphaël Vialle MD PhD ${ }^{1}$
}

\begin{abstract}
M Sanchez, M Delpont, M Bachy, R Kabbaj, D Annequin, R Vialle. How can surgeonfish help pediatric surgeons? A pilot study investigating the antinociceptive effect of fish aquariums in adult volunteers. Pain Res Manag 2015;20(1):e28-e32.
\end{abstract}

BACKGROUND: Multiple distraction strategies have been proposed to reduce the incidence of anxiety and pain in children. Animal-assisted therapy is acknowledged and used in children as an adjunctive treatment with cognitive, physical, psychosocial and spiritual benefits.

OBJECTIVE: To determine the effect of fish aquarium animal-assisted therapy (FA-AAT) on pain perception in a cohort of healthy volunteers. METHODS: Sixty-nine healthy subjects (mean age 27.3 years) were exposed to $>20$ different species of soft or hard corals and $>25$ fish in a $1000 \mathrm{~L}$ saltwater aquarium. Pain perception was assessed using an electrical stimulation device, the Pain Matcher (Cefar Medical AB, Sweden), after $5 \mathrm{~min}, 10 \mathrm{~min}, 20 \mathrm{~min}$ and $30 \mathrm{~min}$ of continuous aquarium viewing. The measurements were repeated $10 \mathrm{~min}$ after stopping aquarium viewing. RESULTS: A statistically significant pain perception threshold augmentation was observed after a 5 min aquarium viewing. This threshold augmentation was also increased after $10 \mathrm{~min}, 20 \mathrm{~min}$ and $30 \mathrm{~min}$ of FA-AAT. A remnant effect was noted up to $10 \mathrm{~min}$ after exposure. This short postviewing time period could be useful in clinical practice to perform certain painful procedures in children, such as those involving needles, under improved conditions immediately after aquarium exposure.

CONCLUSIONS: In the authors' department, FA-AAT is now used as a nonpharmacological antinociceptive technique in association with a protocol of inhalated oxygen/nitrous oxide mixtures for needle-related procedures. Children and parents are invited to watch the aquarium during the $10 \mathrm{~min}$ to $20 \mathrm{~min}$ before venous punctures.

Key Words: Distraction technique; Fish aquarium; Pain; Pain Matcher

\section{Comment le poisson chirurgien peut-il aider les chirurgiens pédiatriques? Une étude pilote sur l'effet antinociceptif des aquariums chez des volontaires adultes}

\begin{abstract}
HISTORIQUE : De multiples stratégies de distraction ont été proposées pour réduire l'incidence d'anxiété et de douleur chez les enfants. La zoothérapie est un traitement d'appoint reconnu et utilisé chez les enfants. Elle s'associe à des avantages physiques, psychosociaux et spirituels.

OBJECTIF : Déterminer l'effet d'une zoothérapie à l'aide d'un aquarium de poissons (ZT-AP) sur la perception de la douleur au sein d'une cohorte de volontaires en santé.

MÉTHODOLOGIE : Soixante-neuf sujets en santé (âge moyen de 27,3 ans) ont été exposés à plus de 20 espèces de coraux mous et durs et plus de 25 poissons dans un aquarium d'eau salée de 1000 litres. Les chercheurs ont évalué la perception de la douleur au moyen d'un dispositif de stimulation électrique, le Pain Matcher (Cefar Medical AB, Suède), au bout de cinq, dix, vingt et trente minutes d'observation continue de l'aquarium. Les mesures ont été reprises dix minutes après l'observation de l'aquarium.

RÉSULTATS : Les chercheurs ont constaté une augmentation statistiquement significative du seuil de perception après l'observation d'un aquarium pendant cinq minutes, ainsi qu'une accentuation de l'augmentation du seuil au bout de dix, 20 et 30 minutes de ZT-AP. Ils ont remarqué un effet résiduel jusqu'à dix minutes après l'exposition. En pratique clinique, cette courte période peut être utile pour effectuer certaines interventions douloureuses chez les enfants (faisant appel à des aiguilles, par exemple), dans des conditions améliorées immédiatement après l'exposition à l'aquarium. CONCLUSIONS : Dans le département des auteurs, la ZT-AP est désormais utilisée comme technique antinociceptive non pharmacologique pour les interventions liées aux aiguilles, en association avec un protocole de mélange d'oxygène et de protoxyde d'azote inhalés. Les enfants et les parents sont invités à observer l'aquarium pendant les dix à 20 minutes précédant une ponction veineuse.
\end{abstract}

Using animals in health care as a therapeutic healing modality has recently gained popularity (12). As the name suggests, animalassisted therapy (AAT) is a goal-directed intervention in which an animal that meets specific criteria is an integral part of a treatment process. AAT is directed and/or delivered by a health/human service professional with specialized expertise in animals and health care, and is designed to promote improvements in human physical, social, emotional and/or cognitive functioning. AAT is acknowledged and used across the health care continuum (in outpatient care and acute care [13] and extended care facilities [14]) as an adjunctive therapy for use by nurses and across all patient populations, from pediatrics (15-17) to geriatrics (18-20). Cognitive, physical, psychosocial and spiritual benefits of AAT include increased attention, orientation and mobility, as well as improved communication and elevated $\operatorname{mood}(21)$. nosis and acupuncture - are used less frequently because of undesirable side effects, time constraints or increased health care costs $(10,11)$.

${ }^{1}$ Université Pierre et Marie Curie-Paris, Armand Trousseau Hospital, Department of paediatric orthopaedics; ${ }^{2}$ Université Pierre et Marie Curie-Paris, Armand Trousseau Hospital, Unité Fonctionnelle d'Analgésie Pédiatrique, Paris Cedex 12, France

Correspondence: Pr Raphaël Vialle, Armand Trousseau Hospital, Department of paediatric orthopaedics, 26, avenue du Docteur Arnold Netter, F-75571 Paris Cedex 12, France. Telephone 33-144736125, fax 33-144736942, e-mail raphael.vialle@trs.aphp.fr 


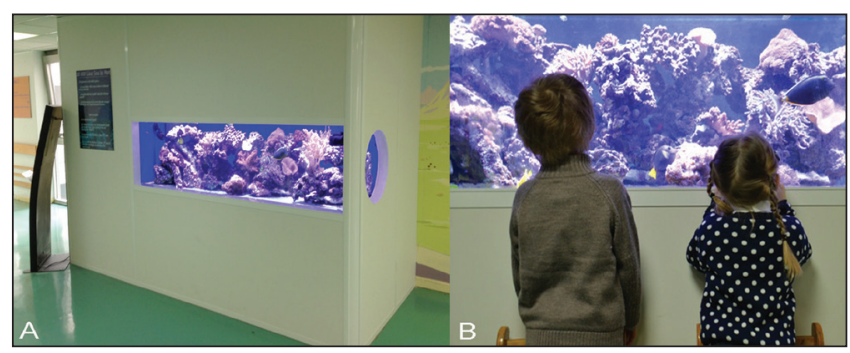

Figure 1) Pictures of the marine aquarium used for subjects' distraction. A The 265-gallon (approximately $1000 \mathrm{~L}$ ) saltwater aquarium was located in the department's main waiting room. Live population included $>20$ species of soft and hard corals and $>25$ fish with a specific lighting system that mimicked natural reef lighting at a depth of $5 \mathrm{~m}$. B Children and parents are invited to watch the aquarium

Because surgery and various invasive procedures generate substantial pain, varying resources and staff trained in caring for pediatric patients make a pediatric surgery department a unique place to care for children in pain. Many recent studies were conducted regarding individual (ie, sex, age) differences in pain perception (15-20). To date, no specific studies have been conducted to investigate the benefit of AAT on pain perception in children or adults. We aimed to evaluate the effects of aquarium therapy (ie, watching fish in the aquarium) because of the relaxation effects observed in elderly patients and patients with Alzheimer's disease $(12,20,22)$. Because of ethics rules and constraints, especially due to the use of an experimental-based pain protocol, we conducted a pilot study involving a cohort of healthy adult volunteers. The purpose of the present study was to determine the effect of fish aquarium AAT (FA-AAT) on volunteers' pain perception, as assessed using a novel testing device (the Pain Matcher; Cefar Medical AB, Sweden).

\section{Population studied}

\section{METHODS}

Sixty-nine healthy subjects (40 women [mean age 28.8 years] and 29 men [mean age 27.3 years]) were recruited among students and trainees in pediatric orthopedics in the department of pediatric orthopedic surgery to participate in the present study. No participants had any skin disease, histamine-induced allergy, asthma, diabetes or pain. Patients had not consumed any medication that was intended for pain or that contained an antihistamine, and none were pregnant. After the experimental procedure was explained, all subjects provided consent before the study. The local Ethics Committee approved the study.

A control group comprised 12 healthy subjects (four men, eight women; mean age 27.4 years) randomly assigned from the cohort of 69 volunteers.

\section{Aquarium installation}

A 265-gallon (approximately 1000 L) saltwater aquarium was used for the protocol (Figure 1). The aquarium was located in the main waiting room of the Department of Pediatric Orthopedics at Armand Trousseau Hospital in Paris, France. The live population included $>20$ different species of soft and hard corals, and $>25$ fish including several species of surgeonfish. The aquarium lighting system consisted of three LED projectors, mimicking natural reef lighting at a water depth of $5 \mathrm{~m}$.

\section{Experimental pain protocol}

Pain perception was assessed using an electrical stimulation device, the Pain Matcher $(23,24)$. The device provides constant current stimulation despite variable skin resistance. It is controlled by a microprocessor, which provides rectangular pulses at a frequency of $10 \mathrm{~Hz}$ and an amplitude of $10 \mathrm{~mA}$. The stimulus intensity is increased by raising from zero to a possible maximum of 396 (in increments of four) over a total of 99 steps. The electrical charge per second is extremely low and causes no tissue damage. The intensity value (0 to 99) relates directly to the pulse width and is displayed on a liquid crystal display screen (Figure 2). The

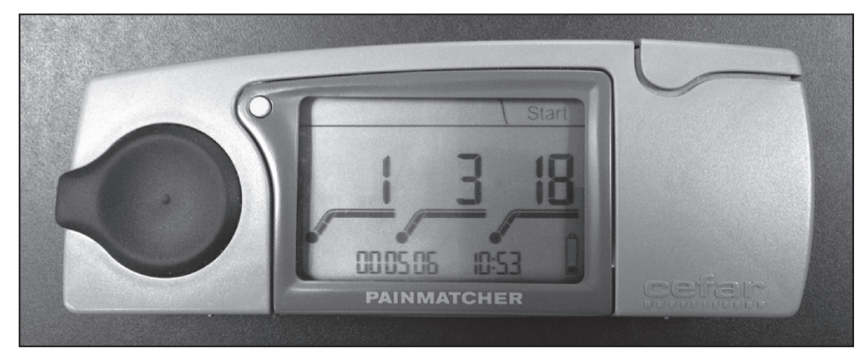

Figure 2) The Pain Matcher (Cefar Medical AB, Sweden) is an instrument for electrical stimulation that provides constant current stimulation despite variable skin resistance. The electrical charge per second is extremely low and causes no tissue damage. The intensity value (0 to 99) is directly related to the pulse width and is displayed on a liquid crystal screen

subjects were instructed to grasp the electrodes of the Pain Matcher between the thumb and index finger of their right hand. The electrical stimulation was started by the subjects, who were told to press a button on the device at the first noticeable sensation (the sensation threshold). Subsequently, the device was restarted, and the subjects were instructed to press the button when the perceived signal became painful (the pain threshold). This method is highly reliable, well tolerated by patients, reported to be easy to use, and may be useful when evaluating pain perception in both patients and control subjects $(23,24)$.

\section{Study procedure}

Measurements were obtained for the 69 subjects to assess thresholds for sensation and pain. Measurements were assessed before aquarium exposure and repeated after $5 \mathrm{~min}, 10 \mathrm{~min}, 20 \mathrm{~min}$ and $30 \mathrm{~min}$ of continuous aquarium contemplation. The subjects were seated comfortably at a distance from $0.5 \mathrm{~m}$ to $1.5 \mathrm{~m}$ in front of the aquarium. They were invited to watch the marine fauna (ie, corals and fish) in a continuous manner. Other distractions (oral communication, cellphones, etc) were not permitted during the aquarium-watching phases. The same measurements were repeated $10 \mathrm{~min}$ after aquarium exposure ended. As a control group, 12 healthy subjects (four men, eight women, mean age 27.4 years), randomly assigned from the cohort of 69 volunteers, were retested for the same thresholds while watching a white wall, without any distractions.

\section{Statistical method}

All data were collected in a computerized database and analyzed using SPSS version 16 (IBM Corporation, USA). The normality of quantitative variables was assessed before testing, using multivariate skewness and kurtosis tests. For data with normal distribution, statistical analysis was performed using paired and unpaired $t$ tests. Statistical differences between sensation and pain thresholds were assessed according to sex and various lengths of aquarium exposure. In the control group, due to a non-normal distribution of data, nonparametric testing was performed using the Wilcoxon signed-rank test; $\mathrm{P}<0.05$ was considered to be statistically significant.

\section{RESULTS}

Table 1 presents median and range (minimum and maximum) values for the first noticeable sensation and the pain threshold Pain Matcher values in both the aquarium and control groups. The normality study showed a normal distribution for sensation values, but not for pain threshold values in the aquarium group. In the control group, the value distribution was not consistent with a normal distribution. Statistical analysis was conducted using a paired $t$ test for sensation values and using a Wilcoxon signed-rank test for pain threshold values in the aquarium group and for all the data in the control group.

Table 2 presents the results of the statistical analysis (paired analysis) comparing Pain Matcher values at different times during aquarium contemplation. No differences between sensation thresholds at different times of the procedure were observed. However, pain thresholds were significantly augmented after $5 \mathrm{~min}, 10 \mathrm{~min}, 20 \mathrm{~min}$ and $30 \mathrm{~min}$ 
TABLE 1

Pain Matcher* threshold values in both groups

\begin{tabular}{|c|c|c|c|c|c|c|}
\hline & \multicolumn{3}{|c|}{ Aquarium group } & \multicolumn{3}{|c|}{ Control group } \\
\hline & Time & Mean & Range & Time, min & Mean & Range \\
\hline \multirow{5}{*}{$\begin{array}{l}\text { First noticeable } \\
\text { sensation }\end{array}$} & Before exposure & 4.07 & $2-8$ & 0 & 4.07 & $3-8$ \\
\hline & $5 \mathrm{~min}$ & 4.03 & $2-7$ & 5 & 3.86 & $3-5$ \\
\hline & $20 \mathrm{~min}$ & 4.04 & $2-7$ & 20 & 4.07 & $3-5$ \\
\hline & $30 \mathrm{~min}$ & 4.22 & $2-8$ & 30 & 3.93 & $2-7$ \\
\hline & $\begin{array}{l}10 \text { min after the } \\
\text { end of exposure }\end{array}$ & 4.20 & $2-10$ & 40 & 4.21 & $3-5$ \\
\hline \multirow[t]{6}{*}{ Pain threshold } & Before exposure & 16.03 & $3-63$ & 0 & 18.43 & $8-68$ \\
\hline & $5 \mathrm{~min}$ & 19.67 & $3-82$ & 5 & 17.57 & $10-34$ \\
\hline & $10 \mathrm{~min}$ & 22.16 & $3-100$ & 10 & 17.64 & $9-42$ \\
\hline & $20 \mathrm{~min}$ & 21.88 & $3-100$ & 20 & 21.79 & $11-86$ \\
\hline & $30 \mathrm{~min}$ & 25.20 & $3-100$ & 30 & 22.21 & $9-86$ \\
\hline & $\begin{array}{l}10 \text { min after the } \\
\text { end of exposure }\end{array}$ & 24.58 & $4-100$ & 40 & 23.71 & $10-99$ \\
\hline
\end{tabular}

${ }^{*}$ Cefar Medical AB, Sweden

of aquarium contemplation compared with initial threshold values before exposure, and they remained significantly higher $10 \mathrm{~min}$ after aquarium contemplation ceased compared with the initial measurement (Figure 3). Statistical analysis revealed no significant difference between pain threshold measures after $30 \mathrm{~min}$ of aquarium exposure and $10 \mathrm{~min}$ after exposure ended (Wilcoxon test; $\mathrm{Z}=-1.591, \mathrm{P}=0.112$ ). These findings suggest a remnant effect of aquarium exposure on healthy subjects.

Control group data analysis showed no statistically significant differences in sensation and pain measurements at any time during the experiment (Table 2).

Despite statistical analysis revealing no differences regarding sensation thresholds according to the sex of subjects exposed to the aquarium, the difference between men and women was very significant regarding pain threshold values. Men had significant higher pain threshold values before aquarium exposure $(\mathrm{P}<0.0001)$. After aquarium contemplation, pain thresholds were increased in both men and women. However, male pain thresholds remained significantly higher than female pain thresholds $(\mathrm{P}=0.001$ to $\mathrm{P}<0.0001$ ) (Table 3$)$.

\section{DISCUSSION}

The relaxing effects of a fish aquarium reported in a literature review $(22,25)$ was the primary motivation for the original installation in a surgery department. Other studies have demonstrated cognitive stimulation in elderly individuals $(18,22)$ and a nutritional intake increase in individuals with Alzheimer's disease after the introduction of fish aquariums (20). Increased comfort levels before dental surgery in patients who have watched fish have suggested an effect on pain control (25). Our study demonstrated a statistically significant increase in pain perception threshold after $5 \mathrm{~min}$ of exposure to aquarium contemplation. This threshold increased again after $10 \mathrm{~min}, 20 \mathrm{~min}$ and $30 \mathrm{~min}$ of FA-AAT compared with baseline levels. A remnant effect was noted up to $10 \mathrm{~min}$ after exposure. This short post-viewing time period could be useful in clinical practice to perform certain painful procedures in children, such as those involving needles, under improved conditions immediately after aquarium exposure. In our department, FA-AAT is now used as a nonpharmacological antinociceptive technique combined with a protocol of inhalational oxygen/nitrous oxide mixtures for needle-related procedures. Children and parents are invited to watch the aquarium for $10 \mathrm{~min}$ to $20 \mathrm{~min}$ before venous punctures.

AAT has gained widespread support and application over the past few decades. During the past decade, it has become more widely accepted that pet ownership and animal assistance in therapy and education may have several positive effects on humans. Controlled studies have shown that petting a companion dog decreases blood pressure in healthy individuals and both decreases blood pressure and increases

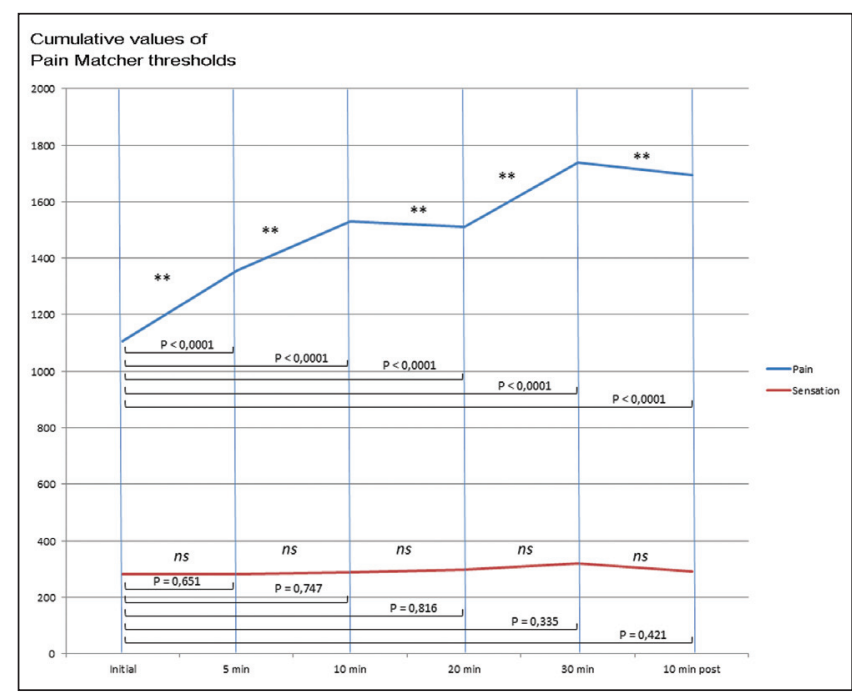

Figure 3) Graphic representation of cumulative values of sensation and pain threshold measurements at different times of the protocol

peripheral skin temperature in individuals with hypertension (12). In treating psychiatric disorders, AAT sessions involving a dog were compared with therapeutic recreation; patients with psychotic disorders, mood disorders and other diagnoses showed statistically reduced anxiety scores after the AAT session (21).

Recent years have witnessed substantially increased research investigating individual differences in pain perception. For example, the literature in this area clearly suggests that men and women differ in their responses to pain, with increased pain sensitivity and risk for clinical pain commonly observed in female subjects $(26,27)$. We also noted this difference in our study, in which pain thresholds were higher in men than in women. Recent studies have demonstrated that anxiety and sex may be influential in determining the relative efficacy of distractionand emotion-based attentional strategies for pain management (28).

Nonpharmacological intervention is a critical component of total stress, anxiety and pain management protocols, and is used as an adjunct to pharmacological treatments $(1,10)$. One example is virtual reality, which has been used effectively to reduce preoperative anxiety and pain perception during pediatric dental treatment (29). Preschool children generally enjoy watching animated cartoons, and they can become sufficiently engrossed as to become oblivious to their surroundings and 
TABLE 2

Statistical analysis regarding Pain Matcher* threshold values in both groups

\begin{tabular}{|c|c|c|c|c|c|c|}
\hline & \multicolumn{3}{|c|}{ Aquarium group } & \multicolumn{3}{|c|}{ Control group } \\
\hline & & $\mathbf{t}$ & & & Z (Wilcoxon & \\
\hline & Delay & (Paired $t$ test) & $\mathbf{P}$ & Delay & signed-ranks test) & $\mathbf{P}$ \\
\hline \multirow{6}{*}{$\begin{array}{l}\text { First noticeable } \\
\text { sensation }\end{array}$} & Before exposure $-5 \mathrm{~min}$ & 0.455 & 0.651 & $0 \min -5 \min$ & -0.551 & 0.582 \\
\hline & Before exposure - $10 \mathrm{~min}$ & 0.323 & 0.747 & $0 \min -10 \min$ & -0.905 & 0.366 \\
\hline & Before exposure $-20 \mathrm{~min}$ & 0.234 & 0.816 & $0 \min -20 \min$ & -0.367 & 0.713 \\
\hline & Before exposure - $30 \mathrm{~min}$ & -0.971 & 0.335 & $0 \min -30 \min$ & -0.155 & 0.877 \\
\hline & $\begin{array}{l}\text { Before exposure - } 10 \text { min after the end of } \\
\text { exposure }\end{array}$ & -0.809 & 0.421 & $0 \min -40 \min$ & -0.734 & 0.463 \\
\hline & & $\mathbf{Z}$ & $\mathbf{P}$ & & $\mathbf{Z}$ & $\mathbf{P}$ \\
\hline \multirow{5}{*}{$\begin{array}{l}\text { Pain threshold } \\
\text { (Wilcoxon signed } \\
\text { ranks test) }\end{array}$} & Before exposure $-5 \mathrm{~min}$ & -5.11 & $<0.0001$ & $0 \min -5 \min$ & -1.268 & 0.205 \\
\hline & Before exposure - $10 \mathrm{~min}$ & -5.98 & $<0.0001$ & $0 \min -10 \min$ & -0.805 & 0.404 \\
\hline & Before exposure - $20 \mathrm{~min}$ & -5.79 & $<0.0001$ & $0 \min -20 \min$ & -0.876 & 0.381 \\
\hline & Before exposure $-30 \mathrm{~min}$ & -6.28 & $<0.0001$ & $0 \min -30 \min$ & -1.379 & 0.168 \\
\hline & $\begin{array}{l}\text { Before exposure - } 10 \text { min after the end of } \\
\text { exposure }\end{array}$ & -6.13 & $<0.0001$ & $0 \min -40 \min$ & -0.035 & 0.972 \\
\hline
\end{tabular}

${ }^{*}$ Cefar Medical AB, Sweden

TABLE 3

Pain Matcher* threshold values in male $(n=29)$ and female $(n=40)$ subjects exposed to the aquarium

\begin{tabular}{|c|c|c|c|c|c|}
\hline & Delay & Sex & Mean \pm SD & $t$ test & $\mathbf{P}$ \\
\hline \multirow{12}{*}{$\begin{array}{l}\text { First noticeable } \\
\text { sensation }\end{array}$} & Before exposure & $M$ & $4.17 \pm 1.31$ & 0.63 & 0.53 \\
\hline & & $\mathrm{F}$ & $4.00 \pm 0.96$ & & \\
\hline & $5 \min$ & M & $4.28 \pm 1.33$ & 1.55 & 0.13 \\
\hline & & $\mathrm{F}$ & $3.85 \pm 0.95$ & & \\
\hline & $10 \min$ & M & $4.24 \pm 1.50$ & 1.20 & 0.24 \\
\hline & & $\mathrm{F}$ & $3.88 \pm 1.04$ & & \\
\hline & $20 \min$ & M & $4.24 \pm 1.09$ & 1.26 & 0.21 \\
\hline & & $\mathrm{F}$ & $3.90 \pm 1.13$ & & \\
\hline & $30 \mathrm{~min}$ & M & $4.38 \pm 1.18$ & 0.90 & 0.37 \\
\hline & & $\mathrm{F}$ & $4.10 \pm 1.34$ & & \\
\hline & $\begin{array}{l}10 \text { min after the } \\
\text { end of exposure }\end{array}$ & M & $4.34 \pm 1.14$ & 0.77 & 0.44 \\
\hline & & $\mathrm{F}$ & $4.10 \pm 1.41$ & & \\
\hline \multirow[t]{12}{*}{ Pain threshold } & Before exposure & M & $22.28 \pm 13.29$ & 4.61 & $<0.0001$ \\
\hline & & $\mathrm{F}$ & $11.50 \pm 5.60$ & & \\
\hline & $5 \min$ & M & $27.28 \pm 16.94$ & 4.31 & $<0.0001$ \\
\hline & & $\mathrm{F}$ & $14.15 \pm 7.85$ & & \\
\hline & $10 \min$ & M & $31.69 \pm 21.71$ & 4.36 & $<0.0001$ \\
\hline & & $\mathrm{F}$ & $15.25 \pm 8.48$ & & \\
\hline & $20 \min$ & M & $28.59 \pm 18.65$ & 3.33 & 0.001 \\
\hline & & $\mathrm{F}$ & $17.03 \pm 9.96$ & & \\
\hline & $30 \mathrm{~min}$ & $M$ & $34.83 \pm 22.96$ & 4.03 & $<0.0001$ \\
\hline & & $\mathrm{F}$ & $18.23 \pm 10.59$ & & \\
\hline & $\begin{array}{l}10 \text { min after the } \\
\text { end of exposure }\end{array}$ & M & $34.48 \pm 26.11$ & 3.62 & 0.001 \\
\hline & & $\mathrm{F}$ & $17.40 \pm 12.36$ & & \\
\hline
\end{tabular}

${ }^{*}$ Cefar Medical AB, Sweden. F Female; M Male

disregard verbal and tactile stimuli $(4,5,9)$. Other forms of distraction have also been tested to reduce the pain and distress experienced by children while undergoing medical procedures. In a comparative study, Hartling et al (3) showed that music may have a positive impact on pain and distress for children during intravenous placement. Benefits were also observed for the parents and health care providers.

We fully recognize the potential for bias in the current study.

The present pilot study aimed to evaluate the distraction caused by marine fish on sensation and pain perception thresholds in healthy adults. Because of ethics rules and constraints, especially due to the use of electrical stimulation by the Pain Matcher, we did not perform this study on a cohort of preoperative children, but we suggest that the distraction effect should be the same, or perhaps higher, in children than in our cohort of healthy adult volunteers. Furthermore, because our study population knew the purpose of the research, it may have impacted the result. Because our study was based on the use of experimentally induced pain, we fully recognize the need to study a sample of children undergoing a needle procedure, for example, to extrapolate the effect of aquarium therapy on procedural pain in children. Such a study is planned for the near future.

Despite the fact that the results from our healthy adult population may not extrapolate to a pediatric population, we expect that aquarium distraction - similar to animated cartoon distraction - would have very beneficial effects on preoperative anxiety, especially among children three to seven years of age (5). We did not assess sensation and pain thresholds after $>30$ min of aquarium exposure because the prolonged test length would bore subjects. Furthermore, we did not assess the remnant effect $>10 \mathrm{~min}$ after the end of aquarium exposure because we found that this time interval was sufficient to perform needle-related procedures, according to our nurses' protocols.

Other objective data, such as levels of anxiety, depression and hostility, could have been tested in our cohort, as in the study by Cole and Gawlinski (12). That study was conducted on 10 patients awaiting orthotopic heart transplantation at the University of California, Los Angeles Medical Center (Los Angeles, USA). A 15-gallon (56.7 L) saltwater fish tank containing multicoloured coral, foliage, stones and four colourful swimming fish of different shapes and sizes was installed in patients' rooms. Although the initiation of FA-AAT produced no difference in levels of anxiety, depression, hostility, dysphoria, positive affect or sensation-seeking in this group of patients, the project had other benefits. Patients expressed delight at having fish aquariums in their rooms, which humanized the environment. As in our department's experience, the aquarium provided cognitive stimulation and became a bridge for communication among patients, family and staff. For months, children and parents considered the fish in the aquarium as valued members of the care team. This program encouraged us to work with such alternative strategies and develop a pain management plan that will provide the greatest benefit. At our institution, children will benefit from both the latest medical approaches and proven, effective alternative therapies.

ACKNOWLEDGMENTS: The authors thank the 'All-marine' team, Mr Fabrice Ortin and Mr Blaise Godard, and Mr Michel Hignette, head of the Porte Dorée Aquarium, for their assistance and support in creation and maintenance of the marine tank.

DISCLOSURES: No funding was received for this work from any of the following organizations or any others: National Institutes of Health, Wellcome Trust, Howard Hughes Medical Institute. 


\section{REFERENCES}

1. Wente SJK. Nonpharmacologic pediatric pain management in emergency departments: A systematic review of the literature. J Emerg Nurs 2013;39:140-50.

2. Ozil C, Vialle R, Thevenin-Lemoine C, Conti E, Annequin D. Use of a combined oxygen/nitrous oxide/morphine chlorydrate protocol for analgesia in burned children requiring painful local care. Pediatr Surg Int 2010;26:263-7.

3. Hartling L, Newton AS, Liang Y, et al. Music to reduce pain and distress in the pediatric emergency department: A randomized clinical trial. JAMA Pediatr 2013;167:826-35.

4. Downey LV, Zun LS. The impact of watching cartoons for distraction during painful procedures in the emergency department. Pediatr Emerg Care 2012;28:1033-5.

5. Lee J, Lee J, Lim H, et al. Cartoon distraction alleviates anxiety in children during induction of anesthesia. Anesth Analg 2012;115:1168-73.

6. Bellieni CV, Cordelli DM, Raffaelli M, Ricci B, Morgese G, Buonocore G. Analgesic effect of watching TV during venipuncture. Arch Dis Child 2006;91:1015-7.

7. Cassidy K-L, Reid GJ, McGrath PJ, et al. Watch needle, watch TV: Audiovisual distraction in preschool immunization. Pain Med 2002;3:108-18.

8. Stinson J, Yamada J, Dickson A, Lamba J, Stevens B. Review of systematic reviews on acute procedural pain in children in the hospital setting. Pain Res Manag 2008;13:51-7.

9. Wu S, Sapru A, Stewart MA, et al. Using acupuncture for acute pain in hospitalized children. Pediatr Crit Care Med 2009;10:291-6.

10. Srouji R, Ratnapalan S, Schneeweiss S. Pain in children: Assessment and nonpharmacological management. Int J Pediatr 2010;2010:1-11.

11. Rosenbaum A, Kain ZN, Larsson P, Lönnqvist P-A, Wolf AR. The place of premedication in pediatric practice. Paediatr Anaesth 2009;19:817-28.

12. Cole KM, Gawlinski A. Animal-assisted therapy: The human-animal bond. AACN Clin Issues 2000;11:139-49.

13. Miller J, Ingram L. Perioperative nursing and animal-assisted therapy. AORN J 2000;72:477-83.

14. Friedmann E, Son H. The human-companion animal bond: How humans benefit. Vet Clin North Am Small Anim Pract 2009;39:293-326.

15. Salgueiro E, Nunes L, Barros A, Maroco J, Salgueiro AI, Dos Santos ME. Effects of a dolphin interaction program on children with autism spectrum disorders: An exploratory research. BMC Res Notes 2012;5:199.

16. Gagnon J, Bouchard F, Landry M, Belles-Isles M, Fortier M, Fillion L. Implementing a hospital-based animal therapy program for children with cancer: A descriptive study. Can Oncol Nurs J 2004; 14:217-22.

17. Bouchard F, Landry M, Belles-Isles M, Gagnon J. A magical dream: A pilot project in animal-assisted therapy in pediatric oncology. Can Oncol Nurs 2004;14:14-7.

18. Kanamori M, Suzuki M, Yamamoto K, et al. A day care program and evaluation of animal-assisted therapy (AAT) for the elderly with senile dementia. Am J Alzheimers Dis Other Demen 2001;16:234-9.

19. Filan SL, Llewellyn-Jones RH. Animal-assisted therapy for dementia: A review of the literature. Int Psychogeriatr 2006;18:597-611.

20. Edwards NE, Beck AM. Animal-assisted therapy and nutrition in Alzheimer's disease. West J Nurs Res 2002;24:697-712.

21. Barker SB, Dawson KS. The effects of animal-assisted therapy on anxiety ratings of hospitalized psychiatric patients. Psychiatr Serv 1998;49:797-801.

22. Riddick C. Health aquariums and the non-institutionalized elderly. In: Sussman MB, ed. Pets and the Family. New-York: Haworth Press 1985;163-72.

23. Stener-Victorin E, Lundeberg T, Kowalski J, Opdal L, Sjöström J, Lundeberg L. Perceptual matching for assessment of itch; reliability and responsiveness analyzed by a rank-invariant statistical method. J Invest Dermatol 2003;121:1301-5.

24. Stener-Victorin E, Kowalski J, Lundeberg T. A new highly reliable instrument for the assessment of pre- and postoperative gynecological pain. Anesth Analg 2002;95:151-7.

25. Katcher A, Segal H, Beck A. Comparison of contemplation and hypnosis for the reduction of anxiety and discomfort during dental surgery. Am J Clin Hypn 1984;27:14-21.

26. Bartley EJ, Fillingim RB. Sex differences in pain: A brief review of clinical and experimental findings. Br J Anaesth 2013;111:52-8.

27. Etherton J, Lawson M, Graham R. Individual and gender differences in subjective and objective indices of pain: Gender, fear of pain, pain catastrophizing and cardiovascular reactivity. Appl Psychophysiol Biofeedback 2014;39:89-97.

28. Thompson T, Keogh E, Chen MJ-L, French CC. Emotion-focused coping and distraction: Sex differences in the influence of anxiety sensitivity during noxious heat stimulation. Eur J Pain 2012;16:410-20.

29. Asl Aminabadi N, Erfanparast L, Sohrabi A, Ghertasi Oskouei S, Naghili A. The impact of virtual reality distraction on pain and anxiety during dental treatment in 4-6 year-old children: A randomized controlled clinical trial. J Dent Res Dent Clin Dent Prospects 2012;6:117-24. 


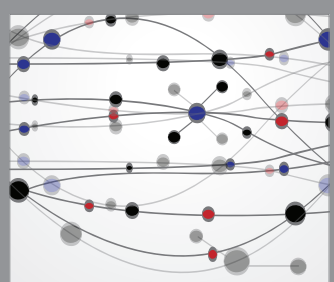

The Scientific World Journal
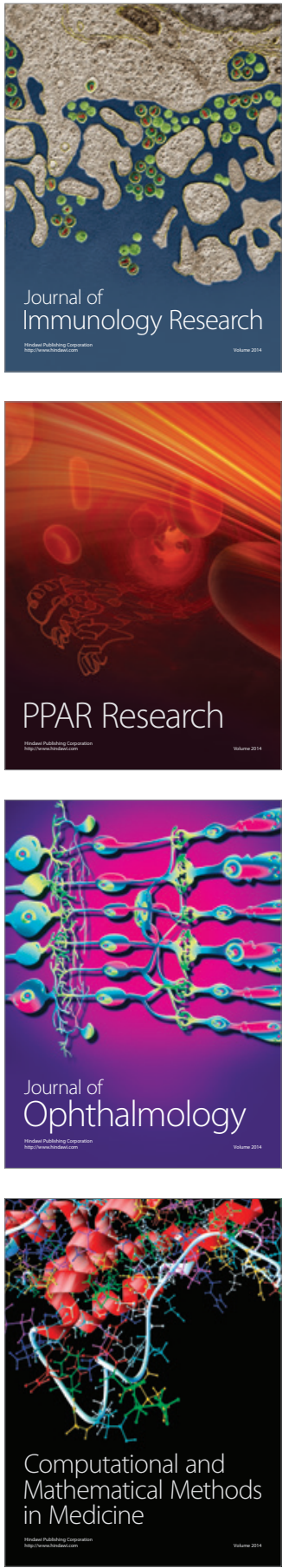

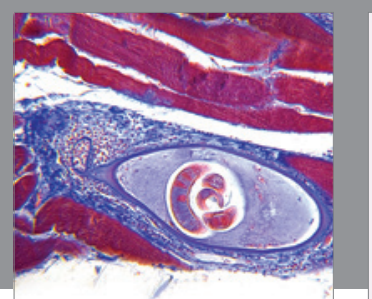

Gastroenterology Research and Practice

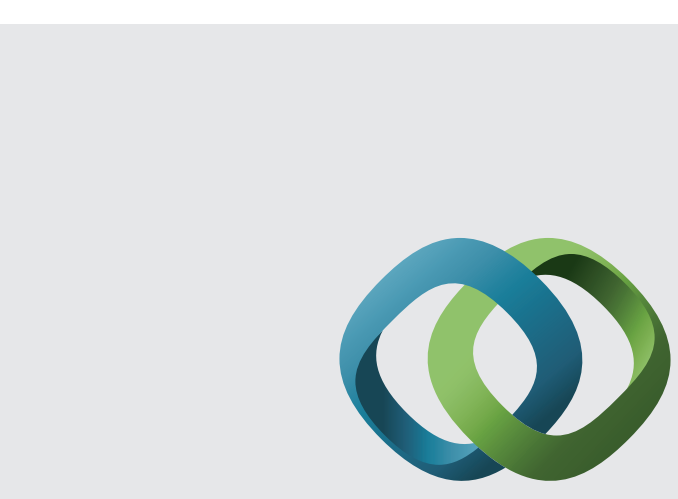

\section{Hindawi}

Submit your manuscripts at

http://www.hindawi.com
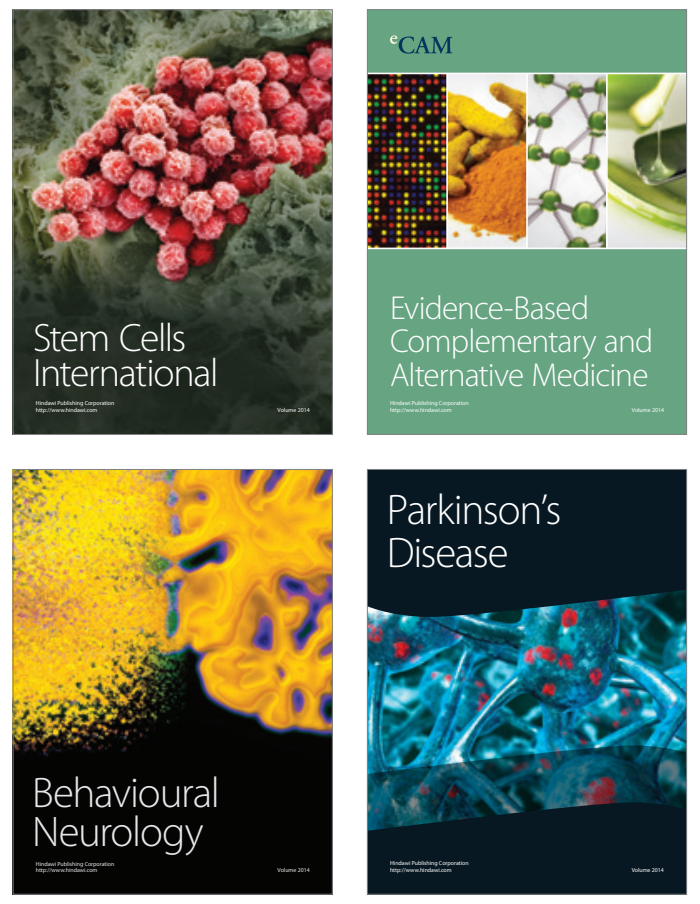
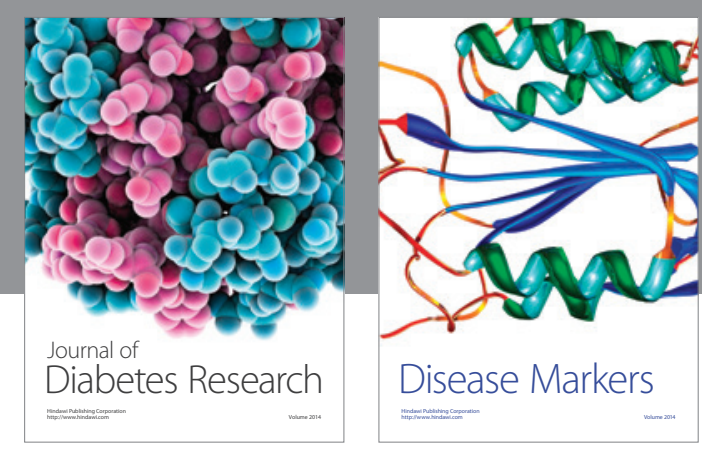

Disease Markers
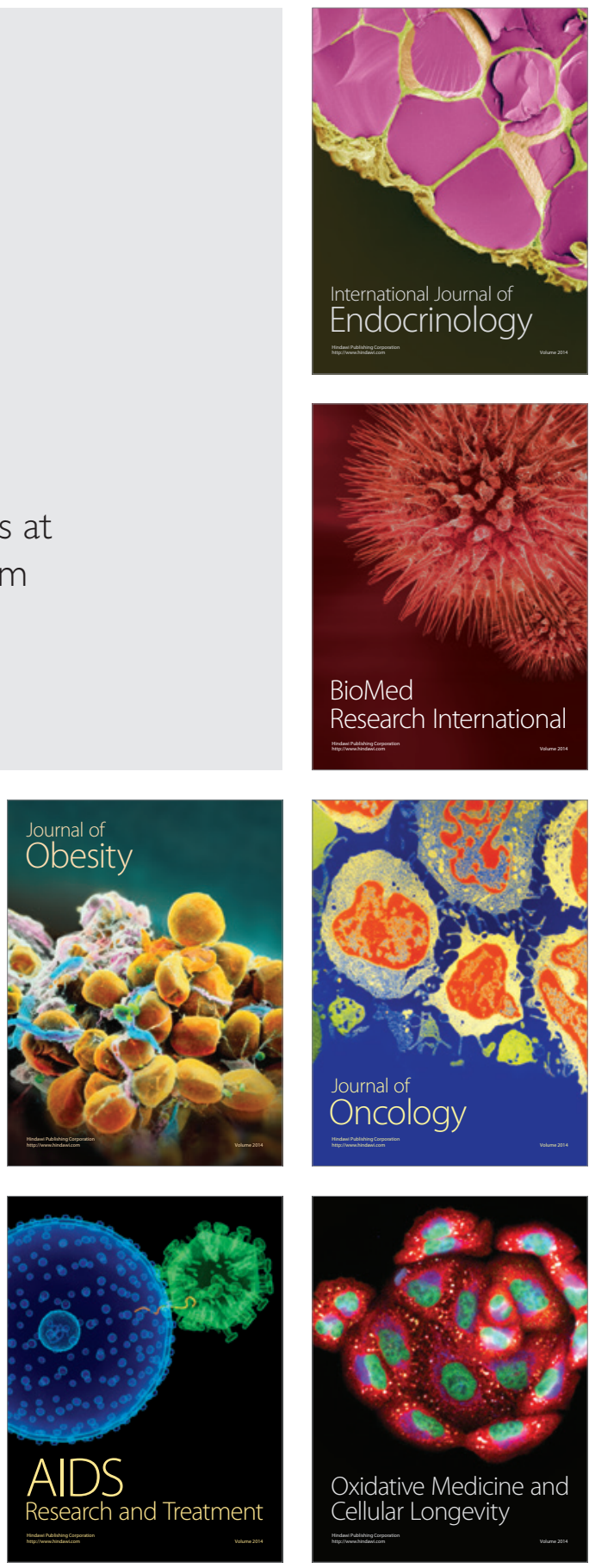